\title{
Scintillation Crystal Type
}

National Cancer Institute

\section{Source}

National Cancer Institute. Scintillation Crystal Type. NCI Thesaurus. Code C116120.

The classification of the crystalline material, which emits light in response to radiation exposure, used in the imaging procedure. 